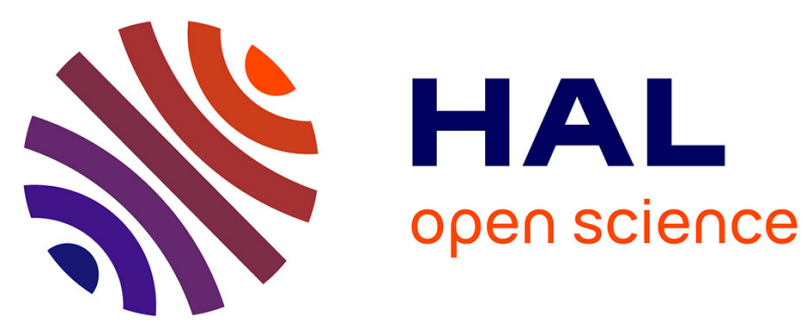

\title{
Second order conic approximation for disassembly line design with joint probabilistic constraints
}

\author{
Mohand Lounes Bentaha, Olga Battaïa, Alexandre Dolgui, S. Jack Hu
}

\section{To cite this version:}

Mohand Lounes Bentaha, Olga Battaïa, Alexandre Dolgui, S. Jack Hu. Second order conic approximation for disassembly line design with joint probabilistic constraints. European Journal of Operational Research, 2015, 247 (3), pp 957-967. 10.1016/j.ejor.2015.06.019 . emse-01184866

\section{HAL Id: emse-01184866 \\ https://hal-emse.ccsd.cnrs.fr/emse-01184866}

Submitted on 1 Aug 2018

HAL is a multi-disciplinary open access archive for the deposit and dissemination of scientific research documents, whether they are published or not. The documents may come from teaching and research institutions in France or abroad, or from public or private research centers.
L'archive ouverte pluridisciplinaire HAL, est destinée au dépôt et à la diffusion de documents scientifiques de niveau recherche, publiés ou non, émanant des établissements d'enseignement et de recherche français ou étrangers, des laboratoires publics ou privés. 


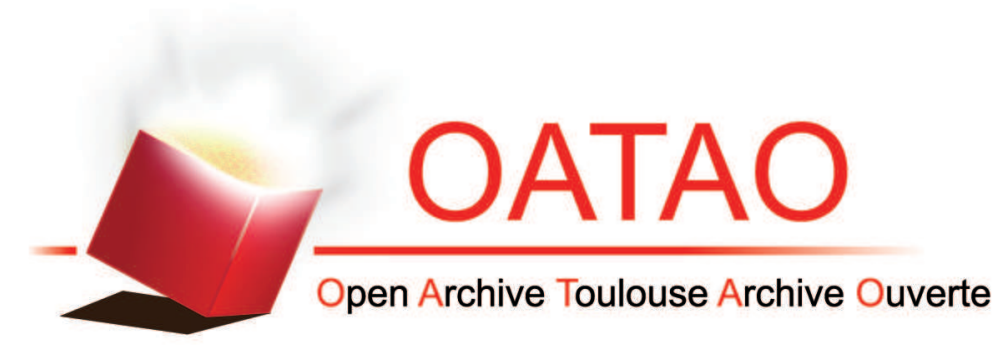

\section{Open Archive Toulouse Archive Ouverte (OATAO)}

OATAO is an open access repository that collects the work of some Toulouse researchers and makes it freely available over the web where possible.

This is an author's version published in: https://oatao.univ-toulouse.fr/20097

Official URL: http://dx.doi.org/10.1016/j.ejor.2015.06.019

\section{To cite this version :}

Bentaha, Mohand Lounes and Battaïa, Olga and Dolgui, Alexandre and Hu, S. Jack Second order conic approximation for disassembly line design with joint probabilistic constraints. (2015) European Journal of Operational Research, 247 (3). 957-967. ISSN 03772217

Any correspondence concerning this service should be sent to the repository administrator: tech-oatao@listes-diff.inp-toulouse.fr 
Innovative Applications of O.R.

\title{
Second order conic approximation for disassembly line design with joint probabilistic constraints
}

\author{
Mohand Lounes Bentaha ${ }^{\mathrm{a}, *}$, Olga Battaïa ${ }^{a}$, Alexandre Dolgui ${ }^{\mathrm{a}}$, S. Jack Hu ${ }^{\mathrm{b}}$ \\ a École Nationale Supérieure des Mines, CNRS UMR6158 LIMOS, F-42023 Saint-Étienne, France \\ ${ }^{\mathrm{b}}$ Department of Mechanical Engineering, The University of Michigan, Ann Arbor, MI, USA
}

Keywords:

Assembly and disassembly

Line design and balancing

Stochastic programming

Joint probabilistic constraints

Piecewise linear approximation

\begin{abstract}
A B S T R A C T
A problem of profit oriented disassembly line design and balancing with possible partial disassembly and presence of hazardous parts is studied. The objective is to design a production line providing a maximal revenue with balanced workload. Task times are assumed to be random variables with known normal probability distributions. The cycle time constraints are to be jointly satisfied with at least a predetermined probability level. An AND/OR graph is used to model the precedence relationships among tasks. Several lower and upper-bounding schemes are developed using second order cone programming and convex piecewise linear approximation. To show the relevance and applicability of the proposed approach, a set of instances from the literature are solved to optimality.
\end{abstract}

\section{Introduction}

Disassembly process plays a crucial role in material and product recovery. It is a required condition for an efficient treatment of endof-life (EOL) products (Ilgin \& Gupta, 2010, 2012). The objective of disassembly is to separate EOL products subassemblies and components for recycling, remanufacturing and reuse. To carry out disassembly operations with higher productivity rate, disassembly lines are used (Güngör \& Gupta, 2002).

From practical point of view, disassembly process is more complex than assembly. In fact, in a disassembly environment, a product is broken down into several components and subassemblies whose quality, quantity and reliability cannot be controlled as in an assembly environment. The structure and quality of EOL products are strongly uncertain and even the number of components in such products can not be predicted. Moreover, an EOL product may contain certain hazardous material which necessitates special handling at a workstation of a disassembly line. Due to technical or economic restrictions such as irreversible connections of components of a product and low revenue obtained from retrieved parts, disassembly is usually a partial process (Lambert, 2002).

\footnotetext{
* Corresponding author. Tel.: +33 678900006; fax: +33 477426666.

E-mail addresses: bentaha@emse.fr, mdlounes.bentaha@gmail.com (M.L. Bentaha), battaia@emse.fr (O. Battaïa), dolgui@emse.fr (A. Dolgui), jackhu@umich.edu (S.J. Hu).
}

Because of the peculiarities given above, the design and balancing of disassembly lines (known as DLBP: disassembly line balancing problem), is a hard optimization problem and needs adapted solution methods. A disassembly line consists of an ordered sequence of workstations connected by a material handling system which is used to transport work-pieces from one workstation to another. As aforementioned, certain parts or subassemblies may be hazardous and require a particular treatment incurring a supplementary cost.

The studied optimization problem consists in assigning a given set of disassembly tasks (of an EOL product) to an ordered sequence of workstations, while respecting precedence and cycle time constraints. Cycle time constraints are to be jointly satisfied with at least a certain probability level $(1-\alpha)$ fixed by the decision maker. Task times are assumed to be independent random variables with known normal probability distributions. The main objective is to maximize the profit produced by the line by optimizing the number of needed workstations of the line and the depth of the disassembly process. Subsequently, the idle times at workstations should be as smooth as possible.

Although the main purpose of this paper is to study stochastic DLBP, it is also shown that the obtained results remain valid for stochastic assembly line design and balancing problem (ALBP).

The paper is organized as follows: Section 2 provides an overview of the relevant literature on disassembly and assembly line design and balancing under uncertainty. A formal description of the studied problem is given in Section 3. Section 4 presents the developed solution approach. Numerical experiments and optimization results 
are presented in Section 5. Section 6 concludes the paper with future research directions.

\section{Literature review}

In this section, papers dealing with line design and balancing under uncertainty of the task processing times for both disassembly and assembly are discussed. In addition, problems that have studied the case of disassembly/assembly processing alternatives are reviewed.

\subsection{Disassembly line design and balancing}

Only limited studies in the literature have taken into account the task processing times variability that characterizes the disassembly context in DLBP. A fuzzy colored Petri net model with a heuristic solution method was proposed in Turowski and Morgan (2005) to study the human factors that cause uncertainty of task times. A collaborative ant colony algorithm for stochastic mixed-model U-shaped DLBP was developed in Agrawal and Tiwari (2006). Task times were assumed to be stochastic with known normal probability distributions. A binary bi-objective non linear program was developed in AydemirKaradag and Turkbey (2013) for DLBP under uncertainty of the task times. Task times were assumed to be independent random variables with known normal probability distributions.

Several mathematical models have also been developed for DLBP under uncertainty of task processing times. In Bentaha, Battaïa, and Dolgui (2014a), uncertainty was modeled using the notion of recourse cost and a sample average approximation method was developed to solve the studied optimization problem. In Bentaha, Battaïa, Dolgui, and $\mathrm{Hu}$ (2014d), uncertainty was modeled using workstation expectation times. In Bentaha, Battaïa, and Dolgui (2014b), a stochastic program was developed for the joint problem of disassembly line balancing and sequencing under uncertainty. In Bentaha, Battaïa, and Dolgui (2014c), a Lagrangian relaxation was proposed to maximize the disassembly line profit under task times variability where workstation expectation times are considered.

To model the possible disassembly process alternatives and precedence relationships among tasks, some of the existing papers have used directed graphs called AND/OR graphs. There are two types of such graphs: AND/OR graphs constituted of tasks and AND/OR graphs constituted of tasks and subassemblies. The first type is considered in (Altekin \& Akkan, 2012; Altekin, Kandiller, \& Ozdemirel, 2008; Güngör \& Gupta, 2001, 2002), the second in (Bentaha et al., 2014a, 2014b, 2014c, 2014d; Koc, Sabuncuoglu, \& Erel, 2009; Lambert, 1999). The latter which includes an explicit representation of subassemblies as well as tasks, is used in this paper. It is explained in detail in Section 3.

\subsection{Assembly line design and balancing}

Even if uncertainty level is lower in assembly, however, different sources from the assembly environment may cause the task time variations, as for example, non qualified operators, machine failures, complex assembly tasks, etc. To deal with this uncertainty, the following models were proposed in the literature. Task times were assumed to be random variables with either known continuous probability distributions (Zhao, Liu, Ohno, \& Kotani, 2007), or known or unknown symmetric probability distributions (Betts \& Mahmoud, 1989; Raouf \& Tsui, 1982), or known independent normal probability distributions. This third case has received quite some attention: earlier papers have focused on optimizing straight assembly lines where heuristic (Carter \& Silverman, 1984; Chakravarty \& Shtub, 1986; Fazlollahtabar, Hajmohammadi, \& Es'haghzadeh, 2011; Kao, 1979; Lyu, 1997; Shin, 1990; Silverman \& Carter, 1986), metaheuristic (Cakir, Altiparmak, \& Dengiz, 2011; Erel, Sabuncuoglu, \& Sekerci, 2005) and exact solution methods (Henig, 1986; Kao, 1976; Sarin, Erel, \& Dar-el, 1999) were proposed. The case of ALBP with station paralleling was studied in (McMullen \& Frazier, 1997). Optimization of U-lines was investigated in (Bagher, Zandieh, \& Farsijani, 2011; Baykasoğlu \& Özbakır, 2007; Chiang \& Urban, 2006; Guerriero \& Miltenburg, 2003; Özcan, Kellegöz, \& Toklu, 2011). Two heuristic approaches to the assembly line re-balancing problem were developed in (Gamberini, Gebennini, Grassi, \& Regattieri, 2009; Gamberini, Grassi, \& Rimini, 2006). In Liu, Ong, and Huang (2005), the authors studied the problem of minimizing the cycle time of the line to be designed.

Robust balancing of assembly lines with interval task times and stability analysis of optimal solutions for ALBP have been proposed, respectively, in (Gurevsky, Hazır, Battaïa, \& Dolgui, 2013b; Hazır \& Dolgui, 2015) and (Gurevsky, Battaïa, \& Dolgui, 2013a; Sotskov, Dolgui, \& Portmann, 2006). Robust balancing of an assembly line with uncertain demand has been presented in Chica, Óscar Cordón, Damas, and Bautista (2013). For cycle time minimization, two robust models and exact solution method for ALBP with interval uncertainty for task times have been proposed in (Hazır \& Dolgui, 2013).

Particularly, for the case of task times following known normal probability distributions, exact and heuristic approaches were designed to solve integer linear programs with disjoint probabilistic constraints, for straight and U-lines (Ağpak \& Gökçen, 2007; Urban \& Chiang, 2006) and two-sided lines (Özcan, 2010).

Modeling of process alternatives and precedence relationships among tasks for assembly line balancing is undertaken in (Capacho \& Pastor, 2006, 2008). The authors introduced and defined a new graph using the notion of Alternative Subgraphs. To solve this problem, an exact approach has been proposed in Scholl, Boysen, and Fliedner (2009) and heuristic approaches in Capacho, Pastor, Dolgui, and Guschinskaya (2007). It should be noted that Alternative Subgraphs graph is exclusively constituted of tasks and does not represent the possible subassemblies as does AND/OR graph used in this study.

As it can be seen, joint satisfaction of cycle time constraints with a certain probability level has not been considered neither for DLBP nor for ALBP. The next section presents the developed formulation for the former problem that with some reduction can be also applied for latter problem.

\section{Problem statement}

The aim is to assign disassembly tasks from set $I$ to an ordered sequence of workstations from set $J$, while satisfying precedence and cycle time constraints under uncertainty of the task processing times. The value of $|J|$ represents the worst case for the number of workstations of the line. For a given problem instance, $|J|$ corresponds to the number of tasks of the longest disassembly process alternative (longest in terms of number of tasks). The goal is to design a line providing the maximal profit and resulting in a number of stations $\mathrm{m}^{*} \leqslant|J|$. Cycle time $\left(C_{t}\right)$ constraints for all workstations have to be jointly respected with at least a probability level $(1-\alpha)$ fixed by the decision maker; $C_{t}$ is the amount of time allocated to each station to complete its assigned tasks. It is the ratio of the planning period length to the number of products that need to be disassembled in order to meet the demand.

The following assumptions are used. A single type discarded product has to be partially (or completely) disassembled on a straight paced line. All received EOL items contain all initial parts with no addition or removing of components. Certain components of the EOL products are hazardous. A task can be performed at any workstation but cannot be split between two workstations. Task processing times are independent from the order in which the tasks are performed. Each component or subassembly has a certain non negative resale value but can be 0 . A fixed cost per operating a time unit of an opened workstation and an additional fixed cost per operating a time unit for treating a hazardous part are given. 


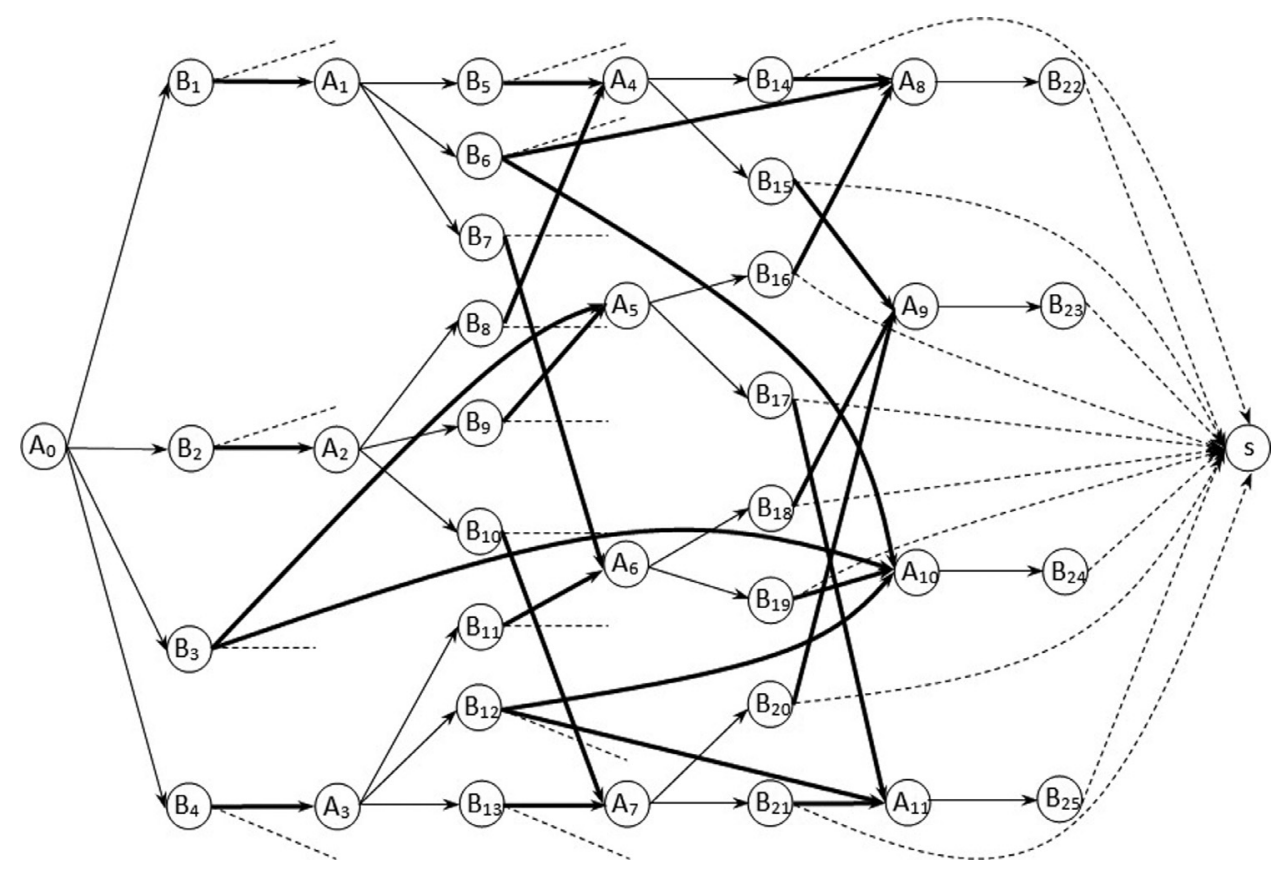

Fig. 1. AND/OR graph of the piston and connecting rod (Bentaha et al., 2013a).

Task times are assumed to be mutually independent random variables with known normal probability distributions, i.e. $t_{i}(\tilde{\xi}) \rightsquigarrow$ $\mathcal{N}\left(\mu_{i}, \sigma_{i}\right), i \in I$. These random variables represent a random vector $\tilde{\xi}=\left(\tilde{t}_{1}, \tilde{t}_{2}, \ldots, \tilde{t}_{|I|}\right)$ varying over a set $\Xi \subset \mathbb{R}_{+}^{|I|}$ given a probability space $(\Xi, \mathcal{F}, P$ ) introduced by $\tilde{\xi}$. The normal-distribution assumption is motivated by its several theoretical characteristics mainly, here, the central limit theorem. The results obtained for the lower and upper bounds can only be used for normal-distribution assumption of the workstation times. The time of a given workstation is the sum of processing times of the tasks assigned to it. This is particularly true for normal-distribution assumption of each task processing time. In the case of task times assumed to be random variables following a different probability distribution, the resulted time of each workstation is not guaranteed to be normally distributed for any number of tasks assigned to it. A disassembly task $i \in H \subset I$ is called hazardous if its execution generates a hazardous subassembly or component. The additional time which could be generated by handling hazardous material is assumed to be taken into account while estimating processing times of the corresponding hazardous tasks.

All possible alternatives for the disassembly process and precedence relationships among tasks and subassemblies, for an EOL product, will be modeled by an AND/OR graph (Bentaha et al., 2013b; Koc et al., 2009). An example of such a graph for the disassembly of a piston and connecting rod (composed of 16 components) is given in Fig. 1. Each subassembly of an EOL product to be disassembled is represented by a node $A_{k}, k \in K$ in the AND/OR graph and each disassembly task by a node $B_{i}, i \in I$. Set $K$ contains the indices of all possible subassemblies that can be generated by the tasks from $I$.

Two types of arcs define the precedence relations between the subassemblies and tasks: AND-type and OR-type arcs. These arcs are represented in the graph with solid lines. For instance, if a task generates two subassemblies, or more, then it is related to these subassemblies by AND-type arcs. If, for a given subassembly, one or more tasks can be performed, but only one must be selected, this subassembly is related to these tasks by OR-type arcs. Table 1 summarizes all possible disassembly tasks that can be performed on the piston and connecting rod. For each task, the corresponding generated components and/or subassemblies are given. In order to handle the case of partial disassembly, where the product is not necessarily disassembled till
Table 1

The piston and connecting rod associated disassembly tasks, components and/or subassemblies.

\begin{tabular}{rlllll}
\hline Task & Subassembly & Components & Task & Subassembly & Components \\
\hline 1 & $1: 9,11,14,16$ & $10 ; 12 ; 13 ; 15$ & 14 & $9,11,14,16$ & $4 ; 5 ; 6 ; 7 ; 8$ \\
2 & $4: 16$ & $1 ; 2 ; 3$ & 15 & $4: 9$ & $11 ; 14 ; 16$ \\
3 & $1: 4 ; 9: 16$ & $5 ; 6 ; 7 ; 8$ & 16 & $9,11,14,16$ & $10 ; 12 ; 13 ; 15$ \\
4 & $1: 9,10,14,15$ & $11 ; 12 ; 13 ; 16$ & 17 & $9,10,14,15$ & $11 ; 12 ; 13 ; 16$ \\
5 & $4: 9,11,14,16$ & $1 ; 2 ; 3$ & 18 & $4: 9$ & $1 ; 2 ; 3$ \\
6 & $1: 4 ; 9,11,14,16$ & $5 ; 6 ; 7 ; 8$ & 19 & $1: 4$ & $5 ; 6 ; 7 ; 8 ; 9$ \\
7 & $1: 9$ & $11 ; 14 ; 16$ & 20 & $4: 9$ & $11 ; 14 ; 15$ \\
8 & $4: 9,11,14,16$ & $10 ; 12 ; 13 ; 15$ & 21 & $9,10,14,15$ & $4 ; 5 ; 6 ; 7 ; 8$ \\
9 & $9: 16$ & $4 ; 5 ; 6 ; 7 ; 8$ & 22 & - & $9 ; 11 ; 14 ; 16$ \\
10 & $4: 9,10,14,15$ & $11 ; 12 ; 13 ; 16$ & 23 & - & $4 ; 5 ; 6 ; 7 ; 8 ; 9$ \\
11 & $1: 9$ & $10 ; 14 ; 15$ & 24 & - & $1 ; 2 ; 3 ; 4$ \\
12 & $1: 4 ; 9,10,14,15$ & $5 ; 6 ; 7 ; 8$ & 25 & - & $9 ; 10 ; 14 ; 15$ \\
13 & $4: 9,10,14,15$ & $1 ; 2 ; 3$ & & & \\
\hline
\end{tabular}

obtaining single components, all tasks are connected (with dashed lines) to the dummy task s introduced into the precedence graph in Fig. 1 as a sink node.

Only a subset $I^{*}$ of set $I$ is selected by the optimization procedure, therefore only the tasks of $I^{*}$ have to be assigned to the workstations of the line. The level of disassembly depends on the profit generated by the corresponding line. The recycling or reuse of certain parts or subassemblies generates profit while the cost of operating opened workstations and additional cost incurred by the treatment of hazardous parts are considered as negative revenue.

The optimization procedure consists of two phases: (1) A number of workstations of the line to be designed is obtained while maximizing line profit. Cycle time constraints are jointly satisfied with at least a probability $(1-\alpha)$. In this first phase, using piecewise linear approximation techniques, several second-order cone programming formulations are developed providing lower and upper bounds on the optimal profit of the line; (2) for the number of workstations obtained in phase 1, an optimal balance is determined. The goal of this second step is to study the impact of balancing the workstations workload on the probability of cycle time constraint satisfaction resulted from the first step. 


\subsection{Phase 1: maximization of the line profit}

Phase 1 consists of maximizing the profit of the line to be designed. The following Chance Constrained 0-1 Binary Program (CCBP) has been developed to formulate this problem.

\section{Parameters}

I: set of disassembly task indices: $I=\{1,2, \ldots, \mathrm{n}\}, \mathrm{n} \in \mathbb{N}^{*}$;

$J$ : set of workstation indices: $J=\{1,2, \ldots, m\}, m \in \mathbb{N}^{*}$;

$K$ : set of indices for the generated subassemblies: $K=\{0,1, \ldots, \mathrm{k}\}, \mathrm{k} \in \mathbb{N}$;

$A_{k}$ : a subassembly, $k \in K$;

$B_{i}$ : a disassembly task, $i \in I$;

s: the AND/OR graph's sink node;

$H$ : hazardous disassembly task index set;

$L$ : parts index set: $L=\{1,2, \ldots, \mid\}, \mid \in \mathbb{N}^{*}$;

$L_{i}$ : set of retrieved parts after execution of a disassembly task $B_{i}$, $i \in I$;

$r_{\ell}:$ revenue generated by part $\ell, \ell \in L$;

$t_{i}(\tilde{\xi})$ : the processing time of task $i, i \in I$, where $t_{i}(\tilde{\xi}) \rightsquigarrow \mathcal{N}\left(\mu_{i}, \sigma_{i}\right)$, $i \in I$;

$\mathrm{C}_{\mathrm{t}}$ : cycle time, $\mathrm{C}_{\mathrm{t}}>0$;

$\mathrm{F}_{\mathrm{c}}$ : fixed cost per time unit for workstations;

$\mathrm{H}_{\mathrm{c}}$ : additional cost per time unit for stations handling hazardous parts;

$P_{k}$ : predecessors index set of $A_{k}, k \in K$, i.e. $P_{k}=\left\{i \mid B_{i}\right.$ precedes $\left.A_{k}\right\}$;

$S_{k}$ : successors index set of $A_{k}, k \in K, S_{k}=\left\{i \mid A_{k}\right.$ precedes $\left.B_{i}\right\}$.

\section{Decision Variables}

$x_{i j}= \begin{cases}1, & \text { if disassembly task } B_{i} \text { is assigned to workstation } j ; \\ 0, & \text { otherwise. }\end{cases}$

$x_{\mathrm{s} j}= \begin{cases}1, & \text { if dummy task } \mathrm{s} \text { is assigned to workstation } j ; \\ 0, & \text { otherwise. }\end{cases}$

$h_{j}= \begin{cases}1, & \text { if a hazardous task is assigned to workstation } j ; \\ 0, & \text { otherwise. }\end{cases}$

Stochastic binary program

$\max \left\{\sum_{i \in I} \sum_{j \in J} \sum_{\ell \in L_{i}} r_{\ell} \cdot x_{i j}-\mathrm{C}_{\mathrm{t}}\left(\mathrm{F}_{\mathrm{c}} \cdot \sum_{j \in J} j \cdot x_{s j}+\mathrm{H}_{\mathrm{c}} \cdot \sum_{j \in J} h_{j}\right)\right\}$

s.t.

$\sum_{i \in S_{0}} \sum_{j \in J} x_{i j}=1$

$\sum_{j \in J} x_{i j} \leqslant 1, \quad \forall i \in I$

$\sum_{i \in S_{k}} \sum_{j \in J} x_{i j} \leqslant \sum_{i \in P_{k}} \sum_{j \in J} x_{i j}, \quad \forall k \in K \backslash\{0\}$

$\sum_{i \in S_{k}} x_{i v} \leqslant \sum_{i \in P_{k}} \sum_{j=1}^{v} x_{i j}, \quad \forall k \in K \backslash\{0\}, \quad \forall v \in J$

$\sum_{j \in J} x_{\mathrm{s} j}=1$

$\sum_{j \in J} j \cdot x_{i j} \leqslant \sum_{j \in J} j \cdot x_{\mathrm{s} j}, \quad \forall i \in I$

$h_{j} \geqslant x_{i j}, \quad \forall j \in J, \quad \forall i \in H$

$P\left(\sum_{i \in I} t_{i}(\tilde{\xi}) \cdot x_{i j} \leqslant \mathrm{C}_{\mathrm{t}}, \forall j \in J\right) \geqslant 1-\alpha$

$x_{\mathrm{s} j}, x_{i j}, h_{j} \in\{0,1\}, \quad \forall i \in I, \quad \forall j \in J$
The terms of the objective function represent, respectively, the earned profit of retrieved parts, the cost of operating workstations and the additional cost for handling hazardous parts. If the dummy task $\mathrm{s}$ is assigned to a workstation $j$, then $j$ defines the number of stations. Constraint (1) imposes the selection of only one disassembly task (OR-successor) to begin the disassembly process. Without loss of generality, we assume that at least one task is required for the disassembly process. Naturally, this task has to be selected from the alternative disassembly tasks realizable for the initial EOL product. Only one alternative has to be selected. The following disassembly options will be determined by the corresponding $A$-node and $B$-nodes connected to it. Constraint set (2) indicates that a task is to be assigned to at most one workstation. Constraints ( 3 ) ensure that only one ORsuccessor is selected. Constraint set (4) defines the precedence relationships among tasks and subassemblies. Constraint (5) imposes the assignment of the dummy task s to one station. Constraints (6) ensure that all selected disassembly tasks are assigned to lower or equal-indexed workstations than the one to which s is assigned. Constraints (7) ensure the value of $h_{j}$ to be 1 if at least one hazardous task is assigned to a workstation $j$. Constraints (8) enforce the station operating time to remain within the cycle time, for all opened workstations, jointly with at least a predefined probability $(1-\alpha)$. Finally, set (9) represents the possible values of the decision variables.

In program (CCBP), let $r_{\ell}=0, \forall \ell \in L_{i}, \forall i \in I, \mathrm{H}_{\mathrm{c}}=0$ and assume that the EOL product is completely disassembled and only one disassembly alternative exists. Then, the objective function of (CCBP) becomes $\max \left\{-\mathrm{C}_{\mathrm{t}} \cdot \mathrm{F}_{\mathrm{c}} \cdot \sum_{j \in J} j \cdot x_{s j}\right\}=-\min \left\{\mathrm{C}_{\mathrm{t}} \cdot \mathrm{F}_{\mathrm{c}} \cdot \sum_{j \in J} j \cdot x_{s j}\right\}$ and there is no $\mathrm{OR}$-precedence relations among tasks and subassemblies; the term $\Sigma_{j \in j} j \cdot x_{s j}$ represents the number of opened workstations. Theoretically, the resulted program defines a simple ALBP of type 1 with stochastic task times and Joint Probabilistic Constraints (JPCALBP). Indeed, the simple ALBP of type 1 is defined as the minimization of the workstations number under AND-precedence relationships among tasks and cycle time constraints.

Along this paper, several lower and upper-bounding schemes will be developed for program (CCBP). From the results above, it follows that these same schemes will be applicable for the stochastic ALBP with joint probabilistic constraints.

\subsection{Phase 2: line balancing}

In phase 1 , a number of workstations $\mathrm{m}^{*} \leqslant|J|$ (where $x_{\mathrm{sm}^{*}}=1$ ) and a subset of tasks $I^{*} \subset I$ are determined. Note that only the set or a subset of tasks of a disassembly alternative is assigned to the stations of the line. An example of such a disassembly alternative and a selected subset $I^{*}$ of disassembly tasks is illustrated in Fig. 2. This selected alternative (in bold) is represented by an AND-graph and $I^{*}=\left\{B_{3}, B_{16}, B_{22}, B_{24}\right\}$. There are no more OR-relations since a decision of disassembling a product (completely in the case of Fig. 2) is made. For this reason, only direct precedence relationships among tasks are considered, i.e. generated subassemblies $\left\{A_{5}, A_{8}, A_{10}\right\}$ are simply deleted. The simple precedence graph in Fig. 3 is then created.

In phase 2, a balance measure is optimized. This measure seeks to assign the disassembly tasks $I^{*}$ to the $\mathrm{m}^{*}$ stations enforcing similar idle time at each workstation. Let $J^{*}=\left\{1,2, \ldots, \mathrm{m}^{*}\right\}, S T_{j}(\tilde{\xi})=$ $\sum_{i \in I^{*}} t_{i}(\tilde{\xi}) \cdot x_{i j}, \forall j \in J^{*}$ and $\operatorname{Pred}(i)=\left\{i^{\prime} \in I^{*} \mid i^{\prime}\right.$ precedes $\left.i\right\}, \forall i \in I^{*}$. The Maximum of the differences among Expectations of Workloads of all workstations is Minimized with the following non linear program (MMEW):

$\min \max _{\forall j, j^{\prime} \in J^{*}, j \neq j^{\prime}}\left|\mathbb{E}_{\tilde{\xi}}\left(S T_{j}(\tilde{\xi})\right)-\mathbb{E}_{\tilde{\xi}}\left(S T_{j^{\prime}}(\tilde{\xi})\right)\right|$

(MMEW)

$\sum_{j \in J^{*}}^{\text {s.t. }} x_{i j}=1, \quad \forall i \in I^{*}$ 


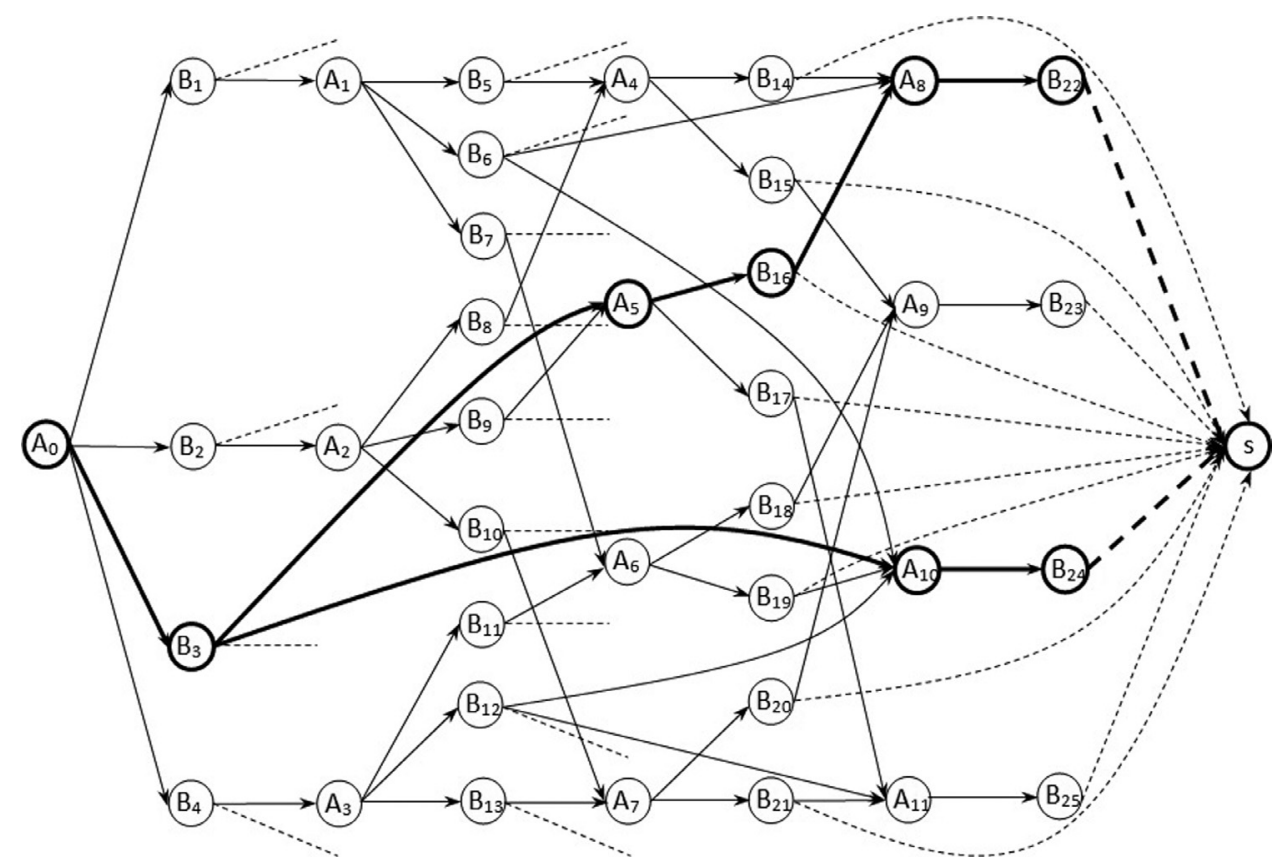

Fig. 2. A selected disassembly alternative.

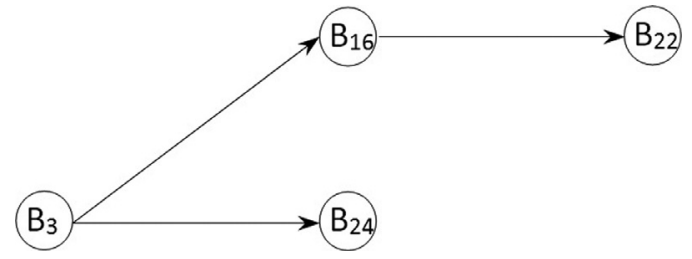

Fig. 3. Precedence AND-graph obtained from the selected disassembly alternative.

$\sum_{j \in J^{*}} j \cdot x_{i^{\prime} j} \leqslant \sum_{j \in J^{*}} j \cdot x_{i j}, \quad \forall i \in I^{*}, \quad \forall i^{\prime} \in \operatorname{Pred}(i)$

$x_{i j} \in\{0,1\}, \quad \forall i \in I^{*}, \quad \forall j \in J^{*}$

To linearize this model, let $\mathcal{B}=\{1,2, \ldots, \mathrm{B}\}, \mathrm{B} \in \mathbb{N}^{*}$ and $S_{l}(\tilde{\xi})=$ $\left(S T_{j}(\tilde{\xi})-S T_{j^{\prime}}(\tilde{\xi}), j, j^{\prime} \in J^{*}, j \neq j^{\prime}\right), l \in \mathcal{B}$, where $B=\left(\begin{array}{c}U^{*} \mid \\ 2\end{array}\right)$; i.e. for each value of $l$ is associated a couple $\left(j, j^{\prime}\right), j, j^{\prime} \in J^{*}, j \neq j^{\prime}$. Then,

$$
\begin{aligned}
\omega_{l} & =\mathbb{E}_{\tilde{\xi}}\left(S_{l}(\tilde{\xi})\right) \\
& =\left(\sum_{i \in I^{*}} \mu_{i} \cdot x_{i j}-\sum_{i \in I^{*}} \mu_{i} \cdot x_{i j^{\prime}}, j, j^{\prime} \in J^{*}, j \neq j^{\prime}\right), \quad l \in \mathcal{B}
\end{aligned}
$$

Thus, the program (MMEW') given below represents a linearized version of program (MMEW).

$\min Y$

MMEW

$$
\begin{aligned}
& \sum_{j \in J^{*}}^{\text {s.t. }} x_{i j}=1, \quad \forall i \in I^{*} \\
& \sum_{j \in J^{*}} j \cdot x_{i^{\prime} j} \leqslant \sum_{j \in J^{*}} j \cdot x_{i j}, \quad \forall i \in I^{*}, \quad \forall i^{\prime} \in \operatorname{Pred}(i) \\
& -Y \leqslant \omega_{l} \leqslant Y, \quad \forall l \in \mathcal{B} \\
& Y \geqslant 0, \quad x_{i j} \in\{0,1\}, \quad \forall i \in I^{*}, \quad \forall j \in J^{*}
\end{aligned}
$$

Constraint set (14) can be replaced with:

$e_{l}+\omega_{l}=Y, \quad \forall l \in \mathcal{B}$

$0 \leqslant e_{l} \leqslant 2 Y, \quad \forall l \in \mathcal{B}$

In this phase, the probability of jointly satisfying cycle time constraints may decrease or increase as a consequence of the possible reassignment of disassembly tasks $I^{*}$. No reassignment of hazardous tasks will be considered. Hence, although the probability mentioned above may decrease or increase, the optimal value of (CCBP) remains unchanged unless this possible decrease or increase of probability will be seen, respectively, as additional cost or profit.

Let $x^{1}$ and $x^{2}$ be, respectively, optimal solutions of problems (CCBP) and (MMEW), and $\mathrm{P}_{1}, \mathrm{P}_{2}$ the corresponding probabilities of jointly satisfying cycle time constraints. The solution $x^{2}$ is retained if

$\varrho=\frac{\mathrm{P}_{1}-\mathrm{P}_{2}}{\mathrm{P}_{1}} \times 100 \leqslant \varpi$

Otherwise, $x^{2}$ is rejected and $x^{1}$ is maintained; $\varpi$ is a percentage fixed by the decision maker. In other words, $x^{2}$ is retained if the percentage of the decrease of the probability in phase 2 does not exceed a certain percentage $\varpi$.

The developed solution approach is detailed in the next section.

\section{Solution method}

In this section, the computational complexity of (CCBP) is first established in subsection 4.1. Then, in order to solve program (CCBP), a lower and several upper-bounding schemes are proposed in subsection 4.2. The development of these schemes is based on convex piecewise linear approximation (Boyd \& Vandenberghe, 2004; Magnani \& Boyd, 2009) and second order cone programming (Alizadeh \& Goldfarb, 2003; Lobo, Vandenberghe, Boyd, \& Lebret, 1998; Nemirovski \& Shapiro, 2007; Prékopa, Yoda, \& Subasi, 2011).

\subsection{Computational complexity study}

Consider the special case of problem (CCBP) defined as follows: task times are deterministic, there is no hazardous task, profits of 
recovered parts are set to 0 , the EOL product is completely disassembled and only one disassembly alternative exists, i.e. precedence relationships among tasks are restricted to AND ones. An instance of such a special case is described with a finite set $\mathscr{I}$ of tasks, task times $t_{i} \in \mathbb{R}_{*}^{+}, i \in \mathscr{I}$, a partial order $\prec$ on $\mathscr{I}$, a number $|\mathscr{J}| \in \mathbb{Z}^{+}$of workstations and a workstation capacity $\mathcal{C}_{\mathrm{t}} \in \mathbb{R}_{*}^{+}$. This defines the general instance of SALBP-1 (Baybars, 1986). The problem SALBP-1 is known to be $\mathcal{N} \mathcal{P}$-hard (Baybars, 1986; Becker \& Scholl, 2006). As a consequence, (CCBP) is a $\mathcal{N} \mathcal{P}$-hard problem.

\subsection{Approximation of (CCBP)}

Let $(1-\alpha)=\bar{\alpha}$. Since disassembly task times are assumed mutually independent random variables with known normal probability distributions, then:

$$
\begin{aligned}
P\left(\sum_{i \in I} t_{i}(\tilde{\xi}) \cdot x_{i j} \leqslant \mathrm{C}_{\mathrm{t}}, \forall j \in J\right) & \geqslant \bar{\alpha} \Longleftrightarrow P\left(\sum_{i \in I} t_{i}(\tilde{\xi}) \cdot x_{i j} \leqslant \mathrm{C}_{\mathrm{t}}\right) \\
& \geqslant \bar{\alpha}^{q_{j}}, \quad \forall j \in J, \quad \sum_{j \in J} q_{j}=1
\end{aligned}
$$

and

$$
\left\{\begin{array}{l}
\forall j \in J: \\
P\left(\sum_{i \in I} t_{i}(\tilde{\xi}) \cdot x_{i j} \leqslant \mathrm{C}_{\mathrm{t}}\right) \geqslant \bar{\alpha}^{q_{j}} \\
\Longleftrightarrow P\left(\frac{\sum_{i \in I} t_{i}(\tilde{\xi}) \cdot x_{i j}-\sum_{i \in I} \mu_{i} \cdot x_{i j}}{\sqrt{\sum_{i \in I} \sigma_{i}^{2} \cdot x_{i j}^{2}}} \leqslant \frac{\mathrm{C}_{\mathrm{t}}-\sum_{i \in I} \mu_{i} \cdot x_{i j}}{\sqrt{\sum_{i \in I} \sigma_{i}^{2} \cdot x_{i j}^{2}}}\right) \geqslant \bar{\alpha}^{q_{j}} \\
\Longleftrightarrow P\left(Z_{j} \leqslant \frac{\mathrm{C}_{\mathrm{t}}-\sum_{i \in I} \mu_{i} \cdot x_{i j}}{\sqrt{\sum_{i \in I} \sigma_{i}^{2} \cdot x_{i j}^{2}}}\right) \geqslant \bar{\alpha}^{q_{j}}, \quad Z_{j} \rightsquigarrow \mathcal{N}(0,1) \\
\Longleftrightarrow \sum_{i \in I} \mu_{i} \cdot x_{i j}+\Phi^{-1}\left(\bar{\alpha}^{q_{j}}\right) \cdot \sqrt{\sum_{i \in I} \sigma_{i}^{2} \cdot x_{i j}^{2}} \leqslant \mathrm{C}_{\mathrm{t}}
\end{array}\right.
$$

Equivalence (19) is obtained in Cheng and Lisser (2012); $\Phi^{-1}(t)$ is the inverse of the standard normal cumulative distribution function $\Phi(t)=\frac{1}{\sqrt{2 \pi}} \int_{-\infty}^{t} \mathrm{e}^{-\frac{r^{2}}{2}} \mathrm{~d} r, t \in \mathbb{R}$.

Let $x$ be a vector of decision variables $x_{i j}, x_{\mathrm{s} j}, h_{j}, \forall i \in I, \forall j \in$ $J$, and $X=\{x \mid$ constraints(1) - (7), (9) are satisfied $\}$. Using the result above, problem (CCBP) is equivalent to the following problem (CCBP'):

$\max \left\{\sum_{i \in I} \sum_{j \in J} \sum_{\ell \in L_{i}} r_{\ell} \cdot x_{i j}-\mathrm{C}_{\mathrm{t}}\left(\mathrm{F}_{\mathrm{c}} \cdot \sum_{j \in J} j \cdot x_{s j}+\mathrm{H}_{\mathrm{c}} \cdot \sum_{j \in J} h_{j}\right)\right\}\left(\mathrm{CCBP}^{\prime}\right)$

s.t.

$\sum_{i \in I} \mu_{i} \cdot x_{i j}+\Phi^{-1}\left(\bar{\alpha}^{q_{j}}\right) \cdot \sqrt{\sum_{i \in I} \sigma_{i}^{2} \cdot x_{i j}^{2}} \leqslant \mathrm{C}_{\mathrm{t}}, \quad \forall j \in J$

$\sum_{j \in J} q_{j}=1$

$x \in X, q_{j} \geqslant 0, \quad \forall j \in J$

Inequalities (21) are second order convex cone constraints. Indeed, let $(v, w) \in \mathbb{R} \times \mathbb{R}^{l-1}$, then

$\mathcal{Q}^{l}=\left\{\left(\begin{array}{c}w \\ v\end{array}\right) \mid v \geqslant\|w\|\right\}$

defines a unit second-order convex cone of dimension $l$; $\|\cdot\|$ refers to the standard Euclidean norm. Since $\alpha<50$ percent ( $\alpha$ is a risk and in general $\alpha \leqslant 10$ percent), then $\Phi^{-1}\left(\bar{\alpha}^{q_{j}}\right)>0$, thus (21) are second-order cone constraints of dimension $l=|I|+1$ since:

$$
\left\{\begin{array}{l}
\sum_{i \in I} \mu_{i} \cdot x_{i j}+\Phi^{-1}\left(\bar{\alpha}^{q_{j}}\right) \cdot \sqrt{\sum_{i \in I} \sigma_{i}^{2} \cdot x_{i j}^{2}} \leqslant \mathrm{C}_{\mathrm{t}}, \quad \forall j \in J \\
\Longleftrightarrow\left\|\Sigma^{\frac{1}{2}} \cdot x_{j}\right\| \leqslant \frac{1}{\Phi^{-1}\left(\bar{\alpha}^{q_{j}}\right)} \cdot\left(\mathrm{C}_{\mathrm{t}}-\mu^{\top} \cdot x_{j}\right), \quad \forall j \in J \\
\Longleftrightarrow\left[\left(\begin{array}{c}
\Sigma^{\frac{1}{2}} \\
\frac{-\mu^{\top}}{\Phi^{-1}\left(\bar{\alpha}^{q_{j}}\right)}
\end{array}\right) x_{j}+\left(\begin{array}{c}
\mathbf{0} \\
\frac{\mathrm{C}_{\mathrm{t}}}{\Phi^{-1}\left(\bar{\alpha}^{q_{j}}\right)}
\end{array}\right)\right] \in \mathcal{Q}^{|I|+1}, \quad \forall j \in J
\end{array}\right.
$$

where $\mu=\left(\mu_{1}, \ldots, \mu_{|I|}\right), x_{j}=\left(x_{1 j}, \ldots, x_{|I| j}\right)^{\top}, \forall j \in J$;

$\Sigma^{\frac{1}{2}}=\operatorname{diag}\left(\sigma_{1}, \ldots, \sigma_{|I|}\right)$ is a diagonal matrix.

The Second Order Cone Mixed Integer Program (SOCMIP) given below represents an equivalent version of problem (CCBP').

$\max \left\{\sum_{i \in I} \sum_{j \in J} \sum_{\ell \in L_{i}} r_{\ell} \cdot x_{i j}-\mathrm{C}_{\mathrm{t}}\left(\mathrm{F}_{\mathrm{c}} \cdot \sum_{j \in J} j \cdot x_{s j}+\mathrm{H}_{\mathrm{c}} \cdot \sum_{j \in J} h_{j}\right)\right\}$

(SOCMIP)

s.t.

$v_{j} \leqslant \frac{1}{\Phi^{-1}\left(\bar{\alpha}^{q_{j}}\right)} \cdot\left(\mathrm{C}_{\mathrm{t}}-\mu^{\top} \cdot x_{j}\right), \quad \forall j \in J$

$w_{i j} \geqslant \sigma_{i} \cdot x_{i j}, \quad \forall i \in I, \quad \forall j \in J$

$v_{j} \geqslant\left\|w_{j}\right\|, \quad \forall j \in J$

$\sum_{j \in J} q_{j}=1$

$x \in X, \quad v_{j} \geqslant 0, \quad w_{i j} \geqslant 0, \quad \forall i \in I, \quad \forall j \in J$

where $v_{j}, w_{i j}, \forall i \in I, \forall j \in J$ are intermediate variables, $w_{j}=$ $\left(w_{1 j}, \ldots, w_{|I| j}\right)^{\top}, \forall j \in J$.

For the sake of compatibility with the literature (Cheng \& Lisser, 2012; Jagannathan, 1974), to make it easier for readers and since $\max \varphi(x)=-\min (-\varphi(x))$, where $\varphi(x)$ is a function of decision variables $x$, in order to approximate (CCBP), minimization version of its objective:

$\min \left\{\mathrm{C}_{\mathrm{t}}\left(\mathrm{F}_{\mathrm{c}} \cdot \sum_{j \in J} j \cdot x_{s j}+\mathrm{H}_{\mathrm{c}} \cdot \sum_{j \in J} h_{j}\right)-\sum_{i \in I} \sum_{j \in J} \sum_{\ell \in L_{i}} r_{\ell} \cdot x_{i j}\right\}$

will be used. The optimal value of the objective function of (CCBP) is then equal to the symmetric value of (30). Let this minimization version be called (M-CCBP).

\subsubsection{Lower bounding scheme for (M-CCBP)}

Problems of chance constrained programming are widely studied in the literature (Blackmore, Ono, \& Williams, 2011; Branda, 2012; DePaolo \& Rader Jr., 2007; Liu, Wen, \& Xu, 2013; Mesfin \& Shuhaimi, 2010; Nemirovski, 2012; Poojari \& Varghese, 2008; Reich, 2013; Shen, Smith, \& Ahmed, 2010; Wang, Guan, \& Wang, 2012; Watanabe \& Ellis, 1994; Zhang \& Li, 2011; Zorgati \& Van Ackooij, 2011). A special case of linear programs with joint probabilistic constraints has been studied in Cheng and Lisser (2012). Coefficients of the constraint matrix were assumed to be normally distributed and the vector rows independent. In our case, the coefficients are the task times and each row vector is composed of the processing times of the tasks assigned to a workstation. It is clear that task times of stations are independent of each other since all task times are already assumed to be mutually independent. Therefore, the main results concerning lower and upper bounds of the continuous program studied in Cheng and Lisser (2012) remain valid for the problem (M-CCBP) with 0-1 binary variables. 
Piecewise tangent approximation of $\Phi^{-1}\left(\bar{\alpha}^{q}\right)$

The piecewise tangent approximation of $\Phi^{-1}\left(\bar{\alpha}^{q}\right)$ is needed in order to define a lower bound of program (CCBP).

The function $\left.\left.\Phi^{-1}\left(\bar{\alpha}^{q}\right), q \in\right] 0,1\right]$ is approximated using the firstorder Taylor series and input data $\left(q_{j}, \Phi^{-1}\left(\bar{\alpha}^{q_{j}}\right)\right), j=1, \ldots, m\left(q_{j}\right.$ is a tangent point). Assume that $q_{1}<q_{2}<\cdots<q_{m}$. A piecewise tangent linear approximation of $\Phi^{-1}\left(\bar{\alpha}^{q}\right)$ is given as follows:

$$
\left\{\begin{array}{l}
\left.\left.g(q)=\max _{j=1, \ldots, m}\left\{a_{j}+b_{j} q\right\}, q \in\right] 0,1\right] \\
b_{j}=\left(\Phi^{-1}\right)^{(1)}\left(\bar{\alpha}^{q_{j}}\right) \cdot \bar{\alpha}^{q_{j}} \ln (\bar{\alpha}), j=1, \ldots, m \\
a_{j}=\Phi^{-1}\left(\bar{\alpha}^{q_{j}}\right)-b_{j} \cdot q_{j}, j=1, \ldots, m \\
\left(\Phi^{-1}\right)^{(1)}\left(\bar{\alpha}^{q_{j}}\right)=\frac{1}{f\left(\Phi^{-1}\left(\bar{\alpha}^{q_{j}}\right)\right)}, j=1, \ldots, m
\end{array}\right.
$$

where $f$ is the standard normal probability density function.

Using approximation (31), program (SOCLB) below is an approximation of (M-CCBP)

$$
\min \left\{\mathrm{C}_{\mathrm{t}}\left(\mathrm{F}_{\mathrm{c}} \cdot \sum_{j \in J} j \cdot x_{s j}+\mathrm{H}_{\mathrm{c}} \cdot \sum_{j \in J} h_{j}\right)-\sum_{i \in I} \sum_{j \in J} \sum_{\ell \in L_{i}} r_{\ell} \cdot x_{i j}\right\}
$$

s.t.

$$
\begin{aligned}
& v_{j} \leqslant C_{\mathrm{t}}-\mu^{\top} \cdot x_{j}, \quad \forall j \in J \\
& w_{i j} \geqslant \sigma_{i} \cdot z_{i j}, \quad \forall i \in I, \quad \forall j \in J \\
& v_{j} \geqslant\left\|w_{j}\right\|, \quad \forall j \in J \\
& z_{i j} \geqslant a_{k} \cdot x_{i j}+b_{k} \cdot y_{i j}, \quad \forall i \in I, \quad \forall j \in J, \quad k=1, \ldots, m \\
& \sum_{j \in J} y_{i j}=\sum_{j \in J} o_{i j}, \quad \forall i \in I \\
& o_{i j} \leqslant x_{i j}, \quad \forall i \in I, \quad \forall j \in J \\
& o_{i j} \leqslant q_{j}, \quad \forall i \in I, \quad \forall j \in J \\
& q_{j}+x_{i j} \leqslant 1+o_{i j}, \quad \forall i \in I, \quad \forall j \in J \\
& \sum_{j \in J} q_{j}=1
\end{aligned}
$$

$x \in X, \quad v_{j}, \quad q_{j}, \quad y_{i j}, \quad w_{i j}, \quad o_{i j}, \quad z_{i j} \geqslant 0, \quad \forall i \in I, \quad \forall j \in J$

Moreover, the optimal value of (SOCLB) is a lower bound of (MCCBP); it is, then, an upper bound of (CCBP). This lower bound is based on the lower bound defined in Cheng and Lisser (2012) for continuous decision variables.

\subsubsection{Upper bounding schemes for (M-CCBP)}

In this subsection, four approximations of (M-CCBP) will be defined, the value of each one represents an upper bound (a lower bound for (CCBP)). They are based on Bonferroni's inequality (Galambos, 1977), Jagannathan's approximation (Jagannathan, 1974), another approximation proposed in Cheng and Lisser (2012) and a variant of Bonferroni's approximation. A piecewise linear approximation of $\Phi^{-1}\left(\bar{\alpha}^{q}\right)$ is given first.
Piecewise linear approximation of $\Phi^{-1}\left(\bar{\alpha}^{q}\right)$

Since $\left.\left.\Phi^{-1}\left(\bar{\alpha}^{q}\right), q \in\right] 0,1\right]$ is convex, for the input data $\left(q_{j}, \Phi^{-1}\left(\bar{\alpha}^{q_{j}}\right)\right), j=1, \ldots, m\left(q_{j}\right.$ is an interpolation point), it follows a piecewise linear approximation $g$ of $\Phi^{-1}\left(\bar{\alpha}^{q}\right)$ :

$\left\{\begin{array}{l}\left.\left.g(q)=\max _{j=1, \ldots, m-1}\left\{a_{j}+b_{j} q\right\}, \quad q \in\right] 0,1\right] \\ a_{j}=\frac{q_{j+1} \Phi^{-1}\left(\bar{\alpha}^{q_{j}}\right)-q_{j} \Phi^{-1}\left(\bar{\alpha}^{q_{j+1}}\right)}{q_{j+1}-q_{j}}, \quad j=1, \ldots, m-1 \\ b_{j}=\frac{\Phi^{-1}\left(\bar{\alpha}^{\left.q_{j+1}\right)-\Phi^{-1}\left(\bar{\alpha}^{q_{j}}\right)}\right.}{q_{j+1}-q_{j}}, \quad j=1, \ldots, m-1 \\ \left.\left.q_{1}<q_{2}<\cdots<q_{m}, \quad q_{j} \in\right] 0,1\right], \quad j=1, \ldots, m\end{array}\right.$

The first upper bound approximation (SOCUB1) of (M-CCBP) is defined by replacing the $\left(a_{k}, b_{k}\right)$ values in (SOCLB) by their values defined in (40). This approximation, based on the one given in Cheng and Lisser (2012), defines an upper bound of (M-CCBP) if

$\gamma=\prod_{j \in J} \Phi\left(\frac{\mathrm{C}_{\mathrm{t}}-\mu^{\top} \cdot x_{j}}{\left\|\Sigma^{\frac{1}{2}} \cdot x_{j}\right\|}\right) \geqslant 1-\alpha$

The second upper bound approximation (SOCUB2) is most common, it is based on Bonferroni's inequality as follows:

$\min \left\{\mathrm{C}_{\mathrm{t}}\left(\mathrm{F}_{\mathrm{c}} \cdot \sum_{j \in J} j \cdot x_{s j}+\mathrm{H}_{\mathrm{c}} \cdot \sum_{j \in J} h_{j}\right)-\sum_{i \in I} \sum_{j \in J} \sum_{\ell \in L_{i}} r_{\ell} \cdot x_{i j}\right\}$

s.t.

$v_{j} \leqslant \frac{1}{\Phi^{-1}\left(1-\alpha_{j}\right)} \cdot\left(\mathrm{C}_{\mathrm{t}}-\mu^{\top} \cdot x_{j}\right), \quad \forall j \in J$

$w_{i j} \geqslant \sigma_{i} \cdot x_{i j}, \quad \forall i \in I, \quad \forall j \in J$

$v_{j} \geqslant\left\|w_{j}\right\|, \quad \forall j \in J$

$x \in X, \quad v_{j}, \quad w_{i j} \geqslant 0, \quad \forall i \in I, \quad \forall j \in J$

where $\alpha_{j}, \forall j \in J$ are parameters verifying $\sum_{j \in J} \alpha_{j}=\alpha$.

The third upper bound (SOCUB3) of (M-CCBP) is defined by replacing $\left(1-\alpha_{j}\right)$ values in (SOCUB2) by $\left(\bar{\alpha}^{q_{j}}\right)$ respectively; $q_{j}, \forall j \in J$ are parameters satisfying $\sum_{j \in J} q_{j}=1$. The fourth upper bound (SOCUB4) is based on Jagannathan's approximation, it is given below.

$\min \left\{\mathrm{C}_{\mathrm{t}}\left(\mathrm{F}_{\mathrm{c}} \cdot \sum_{j \in J} j \cdot x_{s j}+\mathrm{H}_{\mathrm{c}} \cdot \sum_{j \in J} h_{j}\right)-\sum_{i \in I} \sum_{j \in J} \sum_{\ell \in L_{i}} r_{\ell} \cdot x_{i j}\right\}$

(SOCUB4)

s.t.

$\mu^{\top} \cdot x_{j}+o_{j} \cdot \beta_{j} \leqslant \mathrm{C}_{\mathrm{t}}, \quad \forall j \in J$

$\left(x_{j}^{\top} \cdot \Sigma \cdot x_{j}\right)^{\frac{1}{2}} \leqslant \beta_{j}, \quad \forall j \in J$

$\sum_{j \in J} \ln \left(\Phi\left(o_{j}\right)\right) \geqslant \ln (1-\alpha)$

$x \in X, \quad o_{j} \geqslant 0, \quad \forall j \in J$

where $\Phi(t)=P(Z \leqslant t), Z \rightsquigarrow \mathcal{N}(0,1)$ and $\beta_{j}, \forall j \in J$ are parameters which play a key role in the result of this approximation (Jagannathan, 1974); $\Sigma=\left(\Sigma^{1 / 2}\right)^{2^{\prime}}$. The function $\ln \left(\Phi\left(o_{j}\right)\right), j \in J$ has to be approximated using especially convex piecewise linear approximation in order to solve (SOCUB4). The function $\ln \left(\Phi\left(o_{j}\right)\right), j \in J$ is concave, hence, $\ln \left(\frac{1}{\Phi\left(o_{j}\right)}\right)$ is convex. Constraint (45) is equivalently written as:

$\sum_{j \in J} \ln \left(\frac{1}{\Phi\left(o_{j}\right)}\right) \leqslant \ln \left(\frac{1}{1-\alpha}\right)$ 
Lemma. For the input data $\left(q_{j}, \ln \left(\frac{1}{\Phi\left(q_{j}\right)}\right)\right), j=1, \ldots, m$, the function $g$ defined below is a convex piecewise linear approximation of $\ln \left(\frac{1}{\Phi(q)}\right), q \geqslant 0$ :

$\left\{\begin{array}{l}g(q)=\max _{j=1, \ldots, m-1}\left\{a_{j}+b_{j} q\right\}, \quad q \geqslant 0 \\ a_{j}=\frac{q_{j+1} \ln \left(\frac{1}{\Phi\left(q_{j}\right)}\right)-q_{j} \ln \left(\frac{1}{\Phi\left(q_{j+1}\right)}\right)}{q_{j+1}-q_{j}}, \quad j=1, \ldots, m-1 \\ b_{j}=\frac{\ln \left(\frac{1}{\Phi\left(q_{j+1}\right)}\right)-\ln \left(\frac{1}{\Phi\left(q_{j}\right)}\right)}{q_{j+1}-q_{j}}, \quad j=1, \ldots, m-1 \\ q_{1}<q_{2}<\cdots<q_{m}, \quad q_{j} \geqslant 0, \quad j=1, \ldots, m\end{array}\right.$

Proof. Obvious since $\ln \left(\frac{1}{\Phi(q)}\right), \quad q \geqslant 0$, is convex.

Constraint (45) is then replaced by:

$\sum_{j \in J} w_{j} \leqslant \ln \left(\frac{1}{1-\alpha}\right)$

$w_{j} \geqslant a_{k}+b_{k} \cdot o_{j}, \quad \forall j \in J, \quad k=1, \ldots, m-1$

$w_{j} \geqslant 0, \quad \forall j \in J$

\section{Numerical experiments}

Problems (SOCLB), (SOCUB1), (SOCUB2), (SOCUB3), (SOCUB4) and (MMEW') were implemented with MS Visual C++ 2008. ILOG CPLEX 12.4 was used to solve them on a PC with Pentium(R) Dual-Core CPU T4500, 2.30 Gigahertz and 3 Gigabyte RAM. These models have been applied to the problem instance illustrated in Fig. 1 and to five other instances available in the literature. The input data for each instance is given in Table 2. These instances are used as benchmarking problems and contain process alternatives for disassembly. The names of the problem instances are respectively composed of the first letters of authors' names and the year of publication as follows: BBD13 represents a compass (Bentaha et al., 2013c), BBD13a is a piston and connecting rod (Bentaha et al., 2013a), KSE09 is just a sample product created by the authors in Koc et al. (2009), L99a and L99b are respectively a radio set and a ball-point pen (Lambert, 1999) and MJKL11 is an automatic pencil (Ma, Jun, Kim, \& Lee, 2011). In Table 2, the columns 'AND-relations' report the number of disassembly tasks with no successor in subcolumn '0', with one AND-type arc in subcolumn ' 1 ' and with two AND-type arcs in subcolumn ' 2 '. The column 'arcs' gives the total number of AND-type and OR-type arcs.
Table 2

Problem instances.

\begin{tabular}{|c|c|c|c|c|c|c|c|c|c|}
\hline & \multirow[t]{2}{*}{$|I|$} & \multirow[t]{2}{*}{$|K|$} & \multirow[t]{2}{*}{$\mathrm{L}$} & \multirow[t]{2}{*}{ Arcs } & \multicolumn{3}{|c|}{ AND-relations } & \multirow[t]{2}{*}{$|J|$} & \multirow[t]{2}{*}{$C_{t}$} \\
\hline & & & & & 0 & 1 & 2 & & \\
\hline MJKL11 & 37 & 22 & 33 & 76 & 4 & 27 & 6 & 10 & 40 \\
\hline L99a & 30 & 18 & 28 & 60 & 2 & 26 & 2 & 9 & 50 \\
\hline BBD13a & 25 & 11 & 27 & 49 & 4 & 18 & 3 & 4 & 120 \\
\hline KSE09 & 23 & 13 & 20 & 47 & 4 & 14 & 5 & 6 & 20 \\
\hline L99b & 20 & 13 & 23 & 41 & 5 & 9 & 6 & 9 & 10 \\
\hline BBD13 & 10 & 5 & 12 & 18 & 3 & 6 & 1 & 3 & 0.61 \\
\hline
\end{tabular}

Table 3 reports the results of phase 1 obtained for the studied instances using the proposed upper bound and the first lower bound of (CCBP), i.e. the symmetric optimal values of (SOCLB) and (SOCUB1), respectively. These two bounds will be called main bounds. The number of points for convex piecewise linear approximation was $15, \alpha=$ 5 percent, 25 percent of the disassembly tasks were assumed to be hazardous and the first point of input data for piecewise approximation was 0.0001 ; all sampled points were equidistant. The remaining parameters were randomly generated.

Columns ' $U B$ ' and ' $L B$ ' report the upper and lower bound values, respectively. Column 'Gap' reports the optimality gap $\frac{U B-L B}{L B}$. Columns 'm*', ' $\left|I^{*}\right|$ ', 'h-stations' and 'CPU time', in Table 3, report respectively the number of stations, the number of selected tasks, the number of hazardous workstations and the resolution time in seconds; $\gamma=$ $\prod_{j \in J} \Phi\left(\frac{C_{\mathrm{t}}-\mu^{\top} \cdot x_{j}}{\left\|\Sigma^{\frac{1}{2}} \cdot x_{j}\right\|}\right)$. In all tables, a dash '-' means that the corresponding value does not exist.

The obtained results show that, for each problem instance, the line to be designed is composed of at least two workstations. However, a single workstation can be preferred in some cases as shown with instance KSE09. All instances were solved to optimality in short time.

Table 4 presents lower bounds $L B_{\mathrm{Bon}}, L B_{\mathrm{vBon}}$ and $L B_{\mathrm{Jag}}$ of (CCBP) which represent, respectively, the symmetric optimal values of (SOCUB2), (SOCUB3) and (SOCUB4). The number of points in the convex piecewise linear approximation was fixed at 5 . The values $L B_{\mathrm{Bon}}$ and $L B_{\mathrm{vBon}}$ are computed for $\alpha_{j}=\frac{\alpha}{|J|}, \forall j \in J$ and $q_{j}=\frac{1}{|J|}, \forall j \in J$, respectively; $L B_{\text {Jag }}$ is computed for $\beta_{j}=\left(x_{j, \text { Bon }}^{\top} \cdot \Sigma \cdot x_{j, \text { Bon }}\right)^{\frac{1}{2}}, \forall j \in J$, where $x_{j, \text { Bon }}, j \in J$ is an optimal solution of (SOCUB2). This choice of values of parameters $\beta_{j}$ is made in order to avoid infeasibility in solving program (SOCUB4).

Table 4 shows that the returned objective values for all instances were optimal for program (CСB) except the objective value for

Table 3

Obtained results: main lower and upper bounds.

\begin{tabular}{lrrlllrlllll}
\hline & $\mathrm{m}^{*}$ & UB & $\left|I^{*}\right|$ & h-stations & time (second) & $L B$ & $\left|I^{*}\right|$ & h-stations & Time (second) & $\gamma$ percent & Gap percent \\
\hline MJKL11 & 3 & 199 & 6 & 1 & 2.277 & 199 & 6 & 1 & 1.654 & 99.5 \\
L99a & 3 & 48 & 7 & - & 0.218 & 48 & 7 & - & 0.312 & 98.2 \\
BBD13a & 2 & 13 & 3 & - & 0.062 & 13 & 3 & - & 0.094 & 98.7 \\
KSE09 & 1 & 590 & 4 & - & 0.001 & 590 & 4 & - & 0.016 & 97.3 & 0 \\
L99b & 2 & 25 & 6 & - & 0.062 & 25 & 6 & - & 0.078 & 99.4 \\
BBD13 & 2 & 84 & 3 & 1 & 0.078 & 84 & 3 & 1 & 0.202 & 0 \\
\hline
\end{tabular}

Table 4

Obtained results: additional upper bounds.

\begin{tabular}{lrrlrlrl}
\hline & $\mathrm{m}^{*}$ & $L B_{\mathrm{Jag}}$ & Time (second) & $L B_{\text {Bon }}$ & Time (second) & $L B_{\mathrm{vBon}}$ & Time (second) \\
\hline MJKL11 & 3 & 199 & 0.484 & 199 & 0.828 & 199 & 0.577 \\
L99a & 3 & 48 & 0.047 & 48 & 0.079 & 48 & 0.077 \\
BBD13a & 2 & 13 & 0.016 & 13 & 0.015 & 13 & 0.031 \\
KSE09 & 1 & 360 & 0.016 & 590 & 0.016 & 590 & 0.016 \\
L99b & 2 & 25 & 0.031 & 25 & 0.015 & 25 & 0.015 \\
BBD13 & 2 & 84 & 0.062 & 84 & 0.062 & 84 & 0.062 \\
\hline
\end{tabular}


Table 5

Obtained results: idle time leveling.

\begin{tabular}{lrrll}
\hline & $\mathrm{m}^{*}$ & Objective & Reassignment & Time (second) \\
\hline MJKL11 & 3 & 16.00 & 0 & 0.016 \\
L99a & 3 & 7.00 & 0 & 0.031 \\
BBD13a & 2 & 26.00 & $1^{+}$ & 0.001 \\
L99b & 2 & 0.70 & 0 & 0.016 \\
BBD13 & 2 & 0.07 & 0 & 0.001
\end{tabular}

instance KSE09. Programs (SOCUB2) and (SOCUB3) provided optimal values for all processed instances.

In order to analyze the impact of the number of points (or segments) of the piecewise linear functions used to approximate the non linear functions of problems (SOCLB) and (SOCUB1), the benchmark problems were solved for 5 points, 10 points and 20 points. The results have shown that even with 5 interpolation points, (SOCLB) and (SOCUB1) returned optimal objective values for (CCBP).

Table 5 reports the optimization results of the line balancing or idle time leveling phase. In this case, the problem (MMEW') was solved. A reassignment of tasks (of line profit maximization phase) in line balancing phase is represented with value 1 in column 'Reassignment', it is 0 otherwise. This value is $1^{+}$if the reassignment leads to $\mathrm{P}_{2}>\mathrm{P}_{1}$, where $\mathrm{P}_{1}=\prod_{j \in J} \Phi\left(\frac{\mathrm{C}_{\mathrm{t}}-\mu^{\top} \cdot x_{j}^{1}}{\left\|\Sigma^{\frac{1}{2}} \cdot x_{j}^{1}\right\|}\right)$ and $\mathrm{P}_{2}=\prod_{j \in J} \Phi\left(\frac{\mathrm{C}_{\mathrm{t}}-\mu^{\top} \cdot x_{j}^{2}}{\left\|\Sigma^{\frac{1}{2}} \cdot x_{j}^{2}\right\|}\right)$.

In such a case, $x^{2}$, i.e. the solution of line profit maximization phase, is retained with no hesitation. The results have shown that, for in- stance BBD13a, the reassignment of tasks has lead to $P_{2}>P_{1}$. Therefore, the solution $x^{2}$ of line balancing phase should be retained as a final solution.

\section{Optimization results for simple $A L B P-1$}

As for DLBP, two phases were defined for the problem of simple assembly line design with joint probabilistic constraints (JPC-ALBP) introduced in Section 3. The first phase consists in minimizing the number of workstations, the second one in balancing the workload of the line derived from phase 1 . The 25 used instances are available for users on the web site $<$ http://alb.mansci.de $>$. The main parameters of the input data for each instance are given in Table 6; columns ' $|I|$ ', ' $|J|$ ' and ' $C_{\mathrm{t}}$ ' refer, respectively, to the number of assembly tasks, the lower bound on the number of workstations and the cycle time. The tests were realized on the same machine as for DLBP where the resolution time was limited by 1 hour.

Task times for all instances were assumed to be independent normal random variables with known means $\mu_{i}, i \in I$ and standard deviations $\sigma_{i}, i \in I$. The used means are the same as defined on the web site, while standard deviation values are equal to $\mu_{i} / 10, i \in I$. The lower bound $|J|$ is computed as $\left\lceil\sum_{i \in I} \mu_{i} / C_{\mathrm{t}}\right\rceil$. The first phase of JPC-ALBP is solved for $|J|=|J|$, if the defined optimization problem with $|J|$ stations is not feasible, then, it is solved for $|J|+1$ stations, etc, till obtaining a feasible problem. Note that with this procedure, if the problem is feasible for a number of stations $|J|+a$, then this number represents the minimal (optimal) number of workstations.

Table 6

Problem instances for JPC-ALBP.

\begin{tabular}{|c|c|c|c|c|c|c|c|c|c|c|c|}
\hline & $|I|$ & $|J|$ & $C_{t}$ & & $|I|$ & $|J|$ & $C_{t}$ & & $|I|$ & $|J|$ & $C_{t}$ \\
\hline 1. Mertens & 7 & 2 & 18 & 9. Buxey & 29 & 6 & 54 & 17. Wee-mag & 75 & 32 & 47 \\
\hline 2. Bowman & 8 & 4 & 20 & 10. Sawyer & 30 & 5 & 75 & 18. Arcus 1 & 83 & 7 & 10816 \\
\hline 3. Jaeschke & 9 & 3 & 18 & 11. Lutz1 & 32 & 5 & 2828 & 19. Lutz2 & 89 & 24 & 21 \\
\hline 4. Jackson & 11 & 3 & 21 & 12. Gunther & 35 & 6 & 81 & 20. Lutz3 & 89 & 11 & 150 \\
\hline 5. Mansoor & 11 & 2 & 94 & 13. Kilbridge & 45 & 3 & 184 & 21. Mukherje & 94 & 12 & 351 \\
\hline 6. Mitchell & 21 & 3 & 39 & 14. Hahn & 53 & 3 & 4676 & 22. Arcus 2 & 111 & 9 & 17067 \\
\hline 7. Roszieg & 25 & 4 & 32 & 15. Warnecke & 58 & 14 & 111 & 23. Barthol2 & 148 & 25 & 170 \\
\hline 8. Heskiaoff & 28 & 3 & 342 & 16. Tonge & 70 & 7 & 527 & 24. Barthold & 148 & 7 & 805 \\
\hline 25. Scholl & 297 & 25 & 2787 & & & & & & & & \\
\hline
\end{tabular}

Table 7

Obtained results for JPC-ALBP: main lower and upper bounds.

\begin{tabular}{lrlrlll}
\hline & $U B:\left|J^{*}\right|$ & Time (second) & $L B:\left|J^{*}\right|$ & Time (second) & $\gamma$ percent & Gap percent \\
\hline 1. Mertens & 2 & 0.92 & 2 & 0.17 & 99.97 & 0 \\
2. Bowman & 6 & 0.42 & 5 & 0.41 & 96.12 & 20 \\
3. Jaeschke & 3 & 0.09 & 3 & 0.20 & 98.14 & 0 \\
4. Jackson & 3 & 0.20 & 3 & 0.22 & 99.97 & 0 \\
5. Mansoor & 3 & 0.20 & 3 & 0.23 & 96.60 & 0 \\
6. Mitchell & 3 & 0.17 & 3 & 0.36 & 96.67 & 0 \\
7. Roszieg & 5 & 1.25 & 5 & 0.90 & 99.81 & 0 \\
8. Heskiaoff & 4 & 1.78 & 4 & 2.82 & 99.20 & 0 \\
9. Buxey & 8 & 3008.46 & 7 & 2.17 & 99.74 & 14.3 \\
10. Sawyer & 5 & 1.37 & 5 & 1.03 & 97.79 & 0 \\
11. Lutz1 & 6 & 10.31 & 6 & 6.29 & 98.51 & 0 \\
12. Gunther & 8 & 384.71 & 7 & 56.61 & 98.74 & 14.3 \\
13. Kilbridge & 4 & 3.82 & 4 & 2.54 & 99.99 & 0 \\
14. Hahn & 4 & 1.33 & 4 & 1.28 & 96.48 & 0 \\
15. Warnecke & 15 & $>3600$ & 15 & $>3600$ & 96.13 & 0 \\
16. Tonge & 8 & $>3600$ & 8 & 2921.43 & 98.65 & 0 \\
17. Wee-mag & 33 & $>3600$ & 33 & $>3600$ & 97.32 & 0 \\
18. Arcus1 & 8 & $>3600$ & 8 & 454.21 & 96.27 & 0 \\
19. Lutz2 & 25 & $>3600$ & 25 & $>3600$ & 98.53 & 0 \\
20. Lutz3 & 13 & 3072.5 & 12 & $>3600$ & 98.91 & 8.33 \\
21. Mukherje & 13 & $>3600$ & 13 & $>3600$ & 96.76 & 0 \\
22. Arcus2 & 10 & $>3600$ & 10 & $>3600$ & 98.01 & 0 \\
23. Barthol2 & 26 & $>3600$ & 26 & $>3600$ & 97.87 & 0 \\
24. Barthold & 8 & 294.51 & 8 & 265.61 & 96.57 & 0 \\
25. Scholl & 26 & $>3600$ & 26 & $>3600$ & 96.28 & 0 \\
\hline
\end{tabular}


Table 8

Obtained results: JPC-ALBP idle time leveling.

\begin{tabular}{lrll}
\hline & Objective & Reassignment & Time (second) \\
\hline 1. Mertens & 1 & $1^{-}$ & 0.03 \\
3. Jaeschke & 1 & $1^{+}$ & 0.06 \\
4. Jackson & 1 & $1^{+}$ & 0.09 \\
5. Mansoor & 1 & $1^{+}$ & 0.05 \\
6. Mitchell & 0 & $1^{+}$ & 0.06 \\
7. Roszieg & 4 & $1^{+}$ & 0.49 \\
8. Heskiaoff & 0 & $1^{+}$ & 0.16 \\
10. Sawyer & 1 & $1^{+}$ & 4.05 \\
11. Lutz1 & 148 & $1^{+}$ & 1.57 \\
13. Kilbridge & 0 & $1^{+}$ & 0.31 \\
14. Hahn & 665 & $1^{+}$ & 0.95 \\
16. Tonge & 1 & $1^{+}$ & 152.45 \\
18. Arcus1 & 290 & $1^{+}$ & $>3600$ \\
24. Barthold & - & - & $>3600$ \\
\hline
\end{tabular}

Table 7 reports the optimization results of the first phase for the main lower and upper bounds. Columns ' $\left|J^{*}\right|$ ', ' $\left|J^{*}\right|$ ', 'Gap' and 'Time (second)' refer, respectively, to the number of workstations of the upper bound, the number of stations of the lower bound, the optimality gap $\frac{\left|J^{*}\right|-J^{*} \mid}{\left|J^{*}\right|}$ and the resolution time in seconds; ' $\gamma$ ' is $\prod_{j \in J} \Phi\left(\frac{C_{\mathrm{t}}-\mu^{\top} \cdot x_{j}}{\left\|\Sigma^{\frac{1}{2}} \cdot x_{j}\right\|}\right)$. As shown in Table 7, the optimal lower and upper bounds were obtained for all instances, for most of them in less than 1 hour. However, for some instances like Arcus1 and Arcus2, an optimal solution could not be found in 1 hour. The problem JPC-ALBP was solved to optimality for most instances. In such a case, the lower bound $\left|J^{*}\right|$ and upper bound $\left|J^{*}\right|$ values were equal.

The optimization results of the idle time leveling phase are grouped in Table 8. Only instances for which an optimal solution of the problem JPC-ALBP is found in 1 hour were considered. For all processed instances, except for instance Mertens, probabilities of jointly satisfying cycle time constraints were increased. In such cases, the solution of the second phase is preferred to the solution of the first phase since it defines the same objective value and a better balance of the stations workload. The obtained results have shown that although $\mathrm{P}_{1}>\mathrm{P}_{2}$ for instance Mertens, the relative decrease value $\varrho$ of the probability of cycle time constraints satisfaction is smaller than the fixed level $\varpi$. Thus, the solution of the second phase of instance Mertens is retained as well.

The results above demonstrate the efficiency of the proposed mathematical models and solution procedures both for disassembly and assembly lines. Limitations of the developed models concern mainly the normal distribution assumption for the disassembly task durations and their mutual independence. The further work should relax these assumptions.

\section{Conclusion}

In this paper, a profit oriented disassembly line design and balancing problem was studied. The cases of partial disassembly and the presence of hazardous material were integrated and disassembly task times were assumed to be random variables with known normal probability distributions. To solve the addressed problem with an assessment of solution quality, a two phases approach was considered. In the first phase, a mixed integer program with joint probabilistic constraints, along with one lower bound and four upper bounds, were proposed for the line design.

The developed lower and upper bounding schemes were based on second order cone programming and convex piecewise linear approximation. Cycle time constraints were to be jointly respected with at least a probability level fixed by the decision maker. At this phase, the goal was to maximize the line profit. In the second phase, a $0-1$ binary linear programming formulation was developed in order to balance the workload along workstations for the line derived from the first phase.

It is shown, in this study, that under some assumptions the studied problem can be reduced to the assembly line balancing problem. For this reason, the developed optimization procedure can be also applied for the case of assembly.

This paper is the first work dealing with such chance constrained disassembly and assembly problems proposing a lower and several upper bounding schemes and efficient exact models. The developed models were evaluated using a set of instances from the literature. For the disassembly line design phase, all the problem instances were solved to optimality in a short amount of time. As an example, the radio set instance consisting of 30 tasks is solved to optimality in less than 1 second. The results of the line balancing phase showed that it is possible to balance the workload of the designed disassembly line and in the same time improve (increase) the probability of jointly satisfying the cycle time constraints. This fact is occurred with the piston and connecting rod instance, where the probability has passed from 98.0 percent in the line design phase to 98.5 percent in the line balancing phase.

The optimization results in the case of assembly confirmed those of disassembly, mainly, in the line balancing phase. In fact, it is shown that the probability of jointly satisfying cycle time constraints can be increased. In particular, for the 83 tasks instance, this probability has passed from 96.3 percent to 98.2 percent. In the line design phase, the minimal number of workstations for most of the 25 processed instances were determined within reasonable computation time. For example, the 148 tasks instance with cycle time value of 7 is solved in less than 10 minutes.

The optimization results showed that the proposed lower and upper bounding schemes help to solve optimally the defined problems for both assembly and disassembly problem instances.

For future research, a cutting-plane algorithm will be investigated and compared to the default interior point algorithm of the solver Cplex. Other industrial and real life instances for the case of disassembly will also be considered.

\section{References}

Agrawal, S., \& Tiwari, M. K. (2006). A collaborative ant colony algorithm to stochastic mixed-model U-shaped disassembly line balancing and sequencing problem. International Journal of Production Research, 46(6), 1405-1429.

Alizadeh, F., \& Goldfarb, D. (2003). Second-order cone programming. Mathematical Programming, 95(1), 3-51.

Altekin, F. T., \& Akkan, C. (2012). Task-failure-driven rebalancing of disassembly lines. International Journal of Production Research, 50(18), 4955-4976.

Altekin, F. T., Kandiller, L., \& Ozdemirel, N. E. (2008). Profit-oriented disassembly-line balancing. International Journal of Production Research, 46(10), 2675-2693.

Ağpak, K., \& Gökçen, H. (2007). A chance-constrained approach to stochastic line balancing problem. European Journal of Operational Research, 180(3), 1098-1115.

Aydemir-Karadag, A., \& Turkbey, O. (2013). Multi-objective optimization of stochastic disassembly line balancing with station paralleling. Computers E' Industrial Engineering, 65(3), 413-425.

Bagher, M., Zandieh, M., \& Farsijani, H. (2011). Balancing of stochastic U-type assembly lines: an imperialist competitive algorithm. The International Journal of Advanced Manufacturing Technology, 54(1-4), 271-285.

Baybars, I. (1986). A survey of exact algorithms for the simple assembly line balancing problem. Management Science, 32(8), 909-932.

Baykasoğlu, A., \& Özbakır, L. (2007). Stochastic U-line balancing using genetic algorithms. The International Journal of Advanced Manufacturing Technology, 32(1-2), 139-147.

Becker, C. \& Scholl, A. (2006). A survey on problems and methods in generalized assembly line balancing. European Journal of Operational Research, 168(3), 694-715.

Bentaha, M. L., Battaïa, O., \& Dolgui, A. (2013a). Chance constrained programming model for stochastic profit-oriented disassembly line balancing in the presence of hazardous parts. In IFIP advances in information and communication technology: Vol. 414 (pp. 103-110). Berlin Heidelberg: Springer.

Bentaha, M. L., Battaïa, O., \& Dolgui, A. (2013b). A decomposition method for stochastic partial disassembly line balancing with profit maximization. In IEEE conference on automation science and engineering (CASE 2013) (pp. 410-415). IEEE.

Bentaha, M. L., Battaïa, O., \& Dolgui, A. (2013c). A stochastic formulation of the disassembly line balancing problem. In IFIP advances in information and communication technology: Vol. 397 (pp. 397-404). Berlin Heidelberg: Springer. 
Bentaha, M. L., Battaïa, O., \& Dolgui, A. (2014a). A sample average approximation method for disassembly line balancing problem under uncertainty. Computers $\mathcal{E}$ Operations Research, 51, 111-122.

Bentaha, M. L., Battaïa, O., \& Dolgui, A. (2014b). Disassembly line balancing and sequencing under uncertainty. Procedia CIRP, 15, 239-244.

Bentaha, M. L., Battaïa, O., \& Dolgui, A. (2014c). Lagrangian relaxation for stochastic disassembly line balancing problem. Procedia CIRP 2014, 17, 56-60.

Bentaha, M. L., Battaïa, O., Dolgui, A., \& Hu, S. J. (2014d). Dealing with uncertainty in disassembly line design. CIRP Annals - Manufacturing Technology, 63(1), 21-24.

Betts, J., \& Mahmoud, K. I. (1989). Identifying multiple solutions for assembly line balancing having stochastic task times. Computers E Industrial Engineering, 16(3), 427445.

Blackmore, L., Ono, M., \& Williams, B. (2011). Chance-constrained optimal path planning with obstacles. IEEE Transactions on Robotics, 27(6), 1080-1094.

Boyd, S., \& Vandenberghe, L. (2004). Convex Optimization. NY, USA: Cambridge University Press.

Branda, M. (2012). Chance constrained problems: Penalty reformulation and performance of sample approximation technique. Kybernetika, 48(1), 105-122.

Cakir, B., Altiparmak, F., \& Dengiz, B. (2011). Multi-objective optimization of a stochastic assembly line balancing: A hybrid simulated annealing algorithm. Computers $\mathcal{E}$ Industrial Engineering, 60(3), 376-384.

Capacho, L., \& Pastor, R. (2006). The ASALB problem with processing alternatives involving different tasks: Definition, formalization and resolution. In Computational science and its applications - ICCSA 2006: Vol. 3982 (pp. 554-563). Springer-Verlag.

Capacho, L., \& Pastor, R. (2008). ASALBP: the alternative subgraphs assembly line balancing problem. International Journal of Production Research, 46(13), 3503-3516.

Capacho, L., Pastor, R., Dolgui, A., \& Guschinskaya, O. (2007). An evaluation of constructive heuristic methods for solving the alternative subgraphs assembly line balancing problem. Journal of Heuristics, 15(2), 109-132.

Carter, J. C., \& Silverman, F. N. (1984). A cost-effective approach to stochastic line balancing with off-line repairs. Journal of Operations Management, 4(2), 145-157.

Chakravarty, A. K., \& Shtub, A. (1986). A cost minimization procedure for mixed model production lines with normally distributed task times. European Journal of Operational Research, 23(1), 25-36.

Cheng, J., \& Lisser, A. (2012). A second-order cone programming approach for linear programs with joint probabilistic constraints. Operations Research Letters, 40(5), 325-328.

Chiang, W.-C., \& Urban, T. L. (2006). The stochastic U-line balancing problem: A heuristic procedure. European Journal of Operational Research, 175(3), 1767-1781.

Chica, M., Óscar Cordón, Damas, S., \& Bautista, J. (2013). A robustness information and visualization model for time and space assembly line balancing under uncertain demand. International Journal of Production Economics, 145(2), 761-772.

DePaolo, C. A., \& Rader Jr. , D. J. (2007). A heuristic algorithm for a chance constrained stochastic program. European Journal of Operational Research, 176(1), 27-45.

Erel, E., Sabuncuoglu, I., \& Sekerci, H. (2005). Stochastic assembly line balancing using beam search. International Journal of Production Research, 43(7), 1411-1426.

Fazlollahtabar, H., Hajmohammadi, H., \& Es'haghzadeh, A. (2011). A heuristic methodology for assembly line balancing considering stochastic time and validity testing. The International Journal of Advanced Manufacturing Technology, 52(1-4), 311-320.

Galambos, J. (1977). Bonferroni inequalities. The Annals of Probability, 5(4), 577-581.

Gamberini, R. Gebennini, E., Grassi, A., \& Regattieri, A. (2009). A multiple single-pass heuristic algorithm solving the stochastic assembly line rebalancing problem. International Journal of Production Research, 47(8), 2141-2164.

Gamberini, R., Grassi, A., \& Rimini, B. (2006). A new multi-objective heuristic algorithm for solving the stochastic assembly line re-balancing problem. International Journa of Production Economics, 102(2), 226-243.

Guerriero, F., \& Miltenburg, J. (2003). The stochastic U-line balancing problem. Naval Research Logistics (NRL), 50(1), 31-57.

Güngör, A., \& Gupta, S. M. (2001). A solution approach to the disassembly line balancing problem in the presence of task failures. International Journal of Production Research, 39(7), 1427-1467.

Güngör, A., \& Gupta, S. M. (2002). Disassembly line in product recovery. International Journal of Production Research, 40(11), 2569-2589.

Gurevsky, E., Battaïa, O., \& Dolgui, A. (2013). Stability measure for a generalized assembly line balancing problem. Discrete Applied Mathematics, 161(3), 377-394.

Gurevsky, E., Hazır, Ö., Battaïa, O., \& Dolgui, A. (2013). Robust balancing of straight assembly lines with interval task times. Journal of the Operational Research Society. 64(11), 1607-1613.

Hazır, Ö., \& Dolgui, A. (2013). Assembly line balancing under uncertainty: Robust optimization models and exact solution method. Computers $\mathcal{E}$ Industrial Engineering, 65(2), 261-267.

Hazır, Ö., \& Dolgui, A. (2015). A decomposition based solution algorithm for U-type assembly line balancing with interval data. Computers E Operations Research, 59, $126-131$.

Henig, M. I. (1986). Extensions of the dynamic programming method in the deterministic and stochastic assembly-line balancing problems. Computers $\mathcal{E}$ Operations Research, 13(4), 443-449.

Ilgin, M. A., \& Gupta, S. M. (2010). Environmentally conscious manufacturing and product recovery (ECMPRO): A review of the state of the art. Journal of Environmental Management, 91(3), 563-591.

Ilgin, M., \& Gupta, S. (2012). Remanufacturing modeling and analysis. CRC Press.

Jagannathan, R. (1974). Chance-constrained programming with joint constraints. Operations Research, 22(2), 358-372.
Kao, E. P. (1979). Computational experience with a stochastic assembly line balancing algorithm. Computers \& Operations Research, 6(2), 79-86.

Kao, E. P. C. (1976). A preference order dynamic program for stochastic assembly line balancing. Management Science, 22(10), 1097-1104.

Koc, A., Sabuncuoglu, I., \& Erel, E. (2009). Two exact formulations for disassembly line balancing problems with task precedence diagram construction using an AND/OR graph. IIE Transactions, 41(10), 866-881.

Lambert, A. J. D. (1999). Linear programming in disassembly/clustering sequence generation. Computers \& Industrial Engineering, 36(4), 723-738.

Lambert, A. J. D. (2002). Determining optimum disassembly sequences in electronic equipment. Computers E Industrial Engineering, 43, 553-575.

Liu, F., Wen, Z., \& Xu, Y. (2013). A dual-uncertainty-based chance-constrained model for municipal solid waste management. Applied Mathematical Modelling, 37(22), 91479159.

Liu, S., Ong, H., \& Huang, H. (2005). A bidirectional heuristic for stochastic assembly line balancing type II problem. The International Journal of Advanced Manufacturing Technology, 25(1-2), 71-77.

Lobo, M. S., Vandenberghe, L., Boyd, S., \& Lebret, H. (1998). Applications of secondorder cone programming. Linear Algebra and its Applications, 284, 193-228.

Lyu, J. (1997). A single-run optimization algorithm for stochastic assembly line balancing problems. Journal of Manufacturing Systems, 16(3), 204-210.

Ma, Y.-S., Jun, H.-B., Kim, H.-W., \& Lee, D.-H. (2011). Disassembly process planning algorithms for end of life product recovery and environmentally conscious disposal. International Journal of Production Research, 49(23), 7007-7027.

Magnani, A., \& Boyd, S. (2009). Convex piecewise-linear fitting. Optimization and Engineering, $10(1), 1-17$.

McMullen, P. R., \& Frazier, G. V. (1997). A heuristic for solving mixed-model line balancing problems with stochastic task durations and parallel stations. International Journal of Production Economics, 51(3), 177-190.

Mesfin, G., \& Shuhaimi, M. (2010). A chance constrained approach for a gas processing plant with uncertain feed conditions. Computers and Chemical Engineering, 34(8), $1256-1267$.

Nemirovski, A. (2012). On safe tractable approximations of chance constraints. European Journal of Operational Research, 219(3), 707-718.

Nemirovski, A., \& Shapiro, A. (2007). Convex approximations of chance constrained programs. SIAM Journal on Optimization, 17(4), 969-996.

Özcan, U. (2010). Balancing stochastic two-sided assembly lines: A chance-constrained, piecewise-linear, mixed integer program and a simulated annealing algorithm. European Journal of Operational Research, 205(1), 81-97.

Özcan, U., Kellegöz, T., \& Toklu, B. (2011). A genetic algorithm for the stochastic mixedmodel U-line balancing and sequencing problem. International Journal of Production Research, 49(6), 1605-1626.

Poojari, C. A., \& Varghese, B. (2008). Genetic algorithm based technique for solving chance constrained problems. European Journal of Operational Research, 185(3), $1128-1154$.

Prékopa, A., Yoda, K., \& Subasi, M. M. (2011). Uniform quasi-concavity in probabilistic constrained stochastic programming. Operations Research Letters, 39(3), 188-192.

Raouf, A., \& Tsui, C. L. (1982). A new method for assembly line balancing having stochastic work elements. Computers \& Industrial Engineering, 6(2), 131-148.

Reich, D. (2013). A linear programming approach for linear programs with probabilistic constraints. European Journal of Operational Research, 230(3), 487-494.

Sarin, S. C., Erel, E., \& Dar-el, E. M. (1999). A methodology for solving single-model, stochastic assembly line balancing problem. Omega - The International Journal of Management Science, 27, 525-535.

Scholl, A., Boysen, N., \& Fliedner, M. (2009). Optimally solving the alternative subgraphs assembly line balancing problem. Annals of Operations Research, 172(1), 143-258.

Shen, S., Smith, J., \& Ahmed, S. (2010). Expectation and chance-constrained models and algorithms for insuring critical paths. Management Science, 56(10), 1794-1814.

Shin, D. (1990). An efficient heuristic for solving stochastic assembly line balancing problems. Computers \&' Industrial Engineering, 18(3), 285-295.

Silverman, F. N., \& Carter, J. C. (1986). A cost-based methodology for stochastic line balancing with intermittent line stoppages. Management Science, 32(4), 455-463.

Sotskov, Y. N., Dolgui, A., \& Portmann, M.-C. (2006). Stability analysis of an optimal balance for an assembly line with fixed cycle time. European Journal of Operational Research, 168(3), 783-797.

Turowski, M., \& Morgan, M. (2005). Disassembly line design with uncertainty. 2005 IEEE International Conference on Systems, Man and Cybernetics, 1, 954-959.

Urban, T. L., \& Chiang, W.-C. (2006). An optimal piecewise-linear program for the Uline balancing problem with stochastic task times. European Journal of Operational Research, 168(3), 771-782.

Wang, Q., Guan, Y., \& Wang, J. (2012). A chance-constrained two-stage stochastic program for unit commitment with uncertain wind power output. IEEE Transactions on Power Systems, 27(1), 206-215.

Watanabe, T., \& Ellis, H. (1994). A joint chance-constrained programming model with row dependence. European Journal of Operational Research, 77(2), 325-343.

Zhang, H., \& Li, P. (2011). Chance constrained programming for optimal power flow under uncertainty. IEEE Transactions on Power Systems, 26(4), 2417-2424.

Zhao, X., Liu, J., Ohno, K., \& Kotani, S. (2007). Modeling and analysis of a mixed-model assembly line with stochastic operation times. Naval Research Logistics, 54(6), 681691.

Zorgati, R., \& Van Ackooij, W. (2011). Optimizing financial and physical assets with chance-constrained programming in the electrical industry. Optimization and Engineering, 12(1-2), 237-255. 